\title{
The Dialectic of Bottom-up and Top-down Emergence in Social Systems
}

\author{
Christian Fuchs / Wolfgang Hofkirchner
}

ICT\&S Center - Advanced Studies and Research in Information and Communication Technologies \& Society University of Salzburg

christian.fuchs@sbg.ac.at, wolfgang.hofkirchner@sbg.ac.at

\begin{abstract}
In this paper we will present a theoretical explanation of the relationship between so-called individual emergence and the emergence of social systems. We want to take as our point of departure the assumption that from the perspective of hierarchical systems theory self-organization on the level of social systems includes a bottom-up process as well as a topdown process. The bottom-up process refers to what in sociology is called agency, the top-down process refers to what is called structure. We will show that it is convenient to suggest that these processes be linked in a dialectical manner. In this respect we will discuss problems of determinism and indeterminism. This is the background against which we will try to clarify the notion of individual emergence. Our rather general considerations will be illustrated by how ideology, that is consciousness in a collective as well as an individual sense, is conceived of by a number of theories and how it should be conceived of when aspects of self-organization are included.
\end{abstract}

We will conclude with a statement that makes clear why consciousness is a property of individuals that emerges only when individuals participate in society and why society emerges only when individuals are endowed with consciousness.

Keywords: emergence, self-organization, self-organisation, information

Acknowledgement: This paper is a result of research undertaken in the INTAS-research project "Human Strategies in Complexity" (contract number MP/CA 2000-298) and supported by the Austrian Federal Ministry of Education, Science and Culture. It was presented at the conference "Problems of Individual Emergence" organized by: UK Cybernetics Society, Systeemgroep Nederland, Lincoln Research Centre, Center for Innovation and Co-operative Technolog; Amsterdam, April, 16th-20th, 2001.

\section{Emergence and Self-Organization}

Emergence has diachronic as well as synchronous connotations. In the literature they are usually separately referred to as specification and scalar hierarchies among others (Salthe 1996). But it can be shown that both hierarchies are only the two sides of the same coin. A stage concept of systemic evolution may reconcile both of them.

The first connotation of emergence refers to evolutionary development paths where processes of selforganization show so-called meta-system transitions (Heylighen). In the course of evolution one system is linked to another--the old to the new--by emergence, i.e. the first one gives rise to the second and disappears (see Figure 1). 


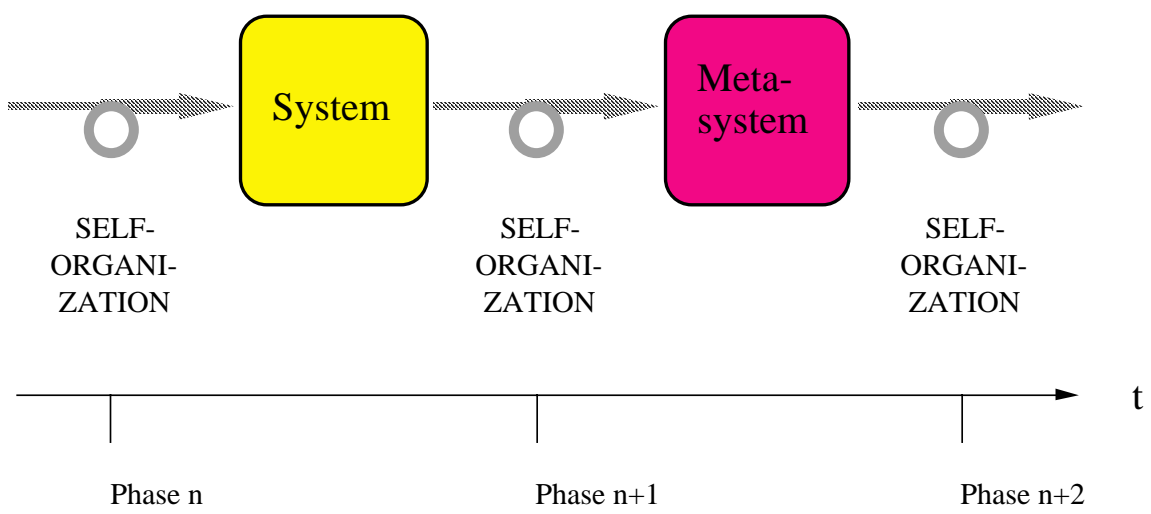

Fig. 1: Diachronic Self-organization

Emergence as the forward loop of self-organisation cycles brings about the change from one system in one phase of evolution to another system in another phase. It moves the historical sequence of the systems.

The second connotation is applied to nested hierarchies of systems in which processes of selforganization take place. The upward process links a system unit to a super-system unit by emergence, i.e. new features appear at the level of the respective super-system unit by virtue of activities at the level of the respective system unit. This kind of emergence is accompanied by a downward process. This downward process is a kind of domination or assertion of superiority. In this way the super-system level both enables and constrains activities at the lower system level (see Figure 2).

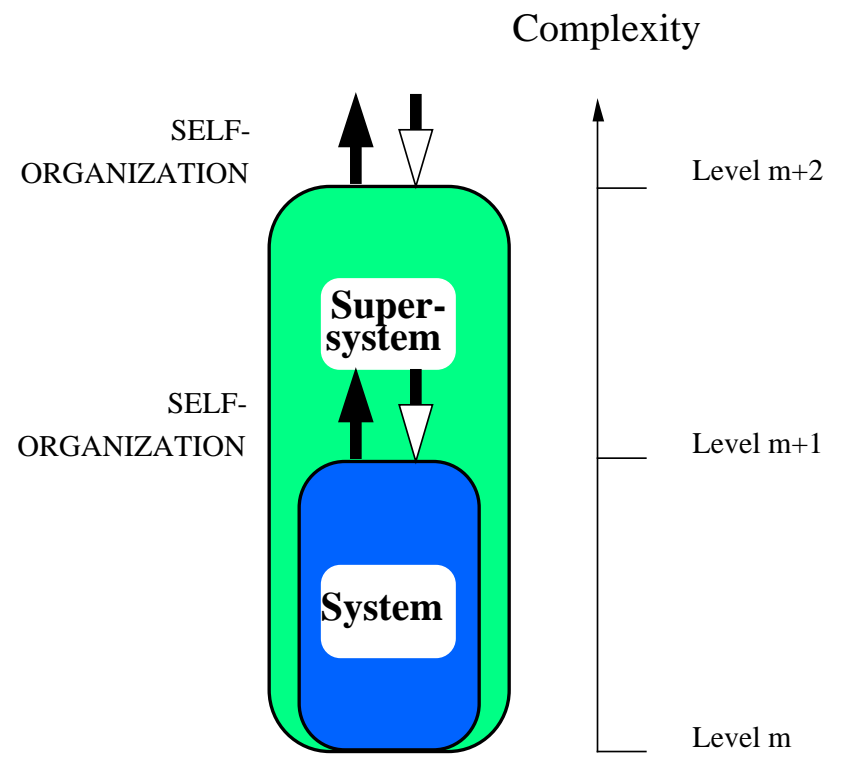

Fig. 2: Synchronous Self-organization

The levels in question may also be referred to as system and subsystem levels. Emergence as an upward loop of self-organisation cycles effects the progression from one system level to a higher system level in encapsulated systems. It propels the structural build-up of systems.

The clue is that both meanings of emergence can be brought together insofar as systems that produce other systems in diachronous processes do so by interlocking their behaviour, in other words by coherent interactions; the new system has a hierarchical character enabling synchronous processes between the two levels; i.e., meta-systems turn out to be super-systems in which the systems that diachronously constitute the new holistic entity are in the Hegelian sense synchronously "sublated" ("aufgehoben") as 
constituent parts. That is, the old system is overcome, but conserved by the new one. Thus, a stage model which combines both so-called specification and scalar hierarchies can be sketched (see Figure 3).

It is a phase model and a layer model in one. The dimension left to right represents the diachronous aspects and the dimension bottom to top, the synchronous ones. The shift from one phase to a subsequent phase is tantamount to a shift unto a new layer. The new system includes this additional layer. It encapsulates what previously were autonomous systems as subsystems and shapes them to reflect the dominance relation. However, the newly formed system will always depend on the functioning of its subsystems. When they cease to support the system, it will break down. Emergence brings forth new systems and sustains their build-up.

An as yet-to-be-developed theory of evolutionary systems would seek to show reality to be the totality of the systems that have given rise to one another, continue to influence each other, and remain in a state of constant development. From this perspective of systemic evolution, the world may be understood as a system of systems that organises itself, i.e. that created itself and continues to develop itself. The systems have subordinate subsystems and are themselves components of higher level systems. Together they form a layered structure in which the systems that arose at later stages of the evolutionary process are found at higher levels, just as the older systems are found at lower levels. The higher levels of the systems rest on the lower ones both structurally and as processes; the lower ones allow for further development at the same level and (when the performance of system-specific functions there reaches its limit) the higher organization of the systems at the next level may or may not be realized by the systems. The lower levels form quasi-potential preliminary stages for higher level development, but they do not determine the development at the higher level in detail.

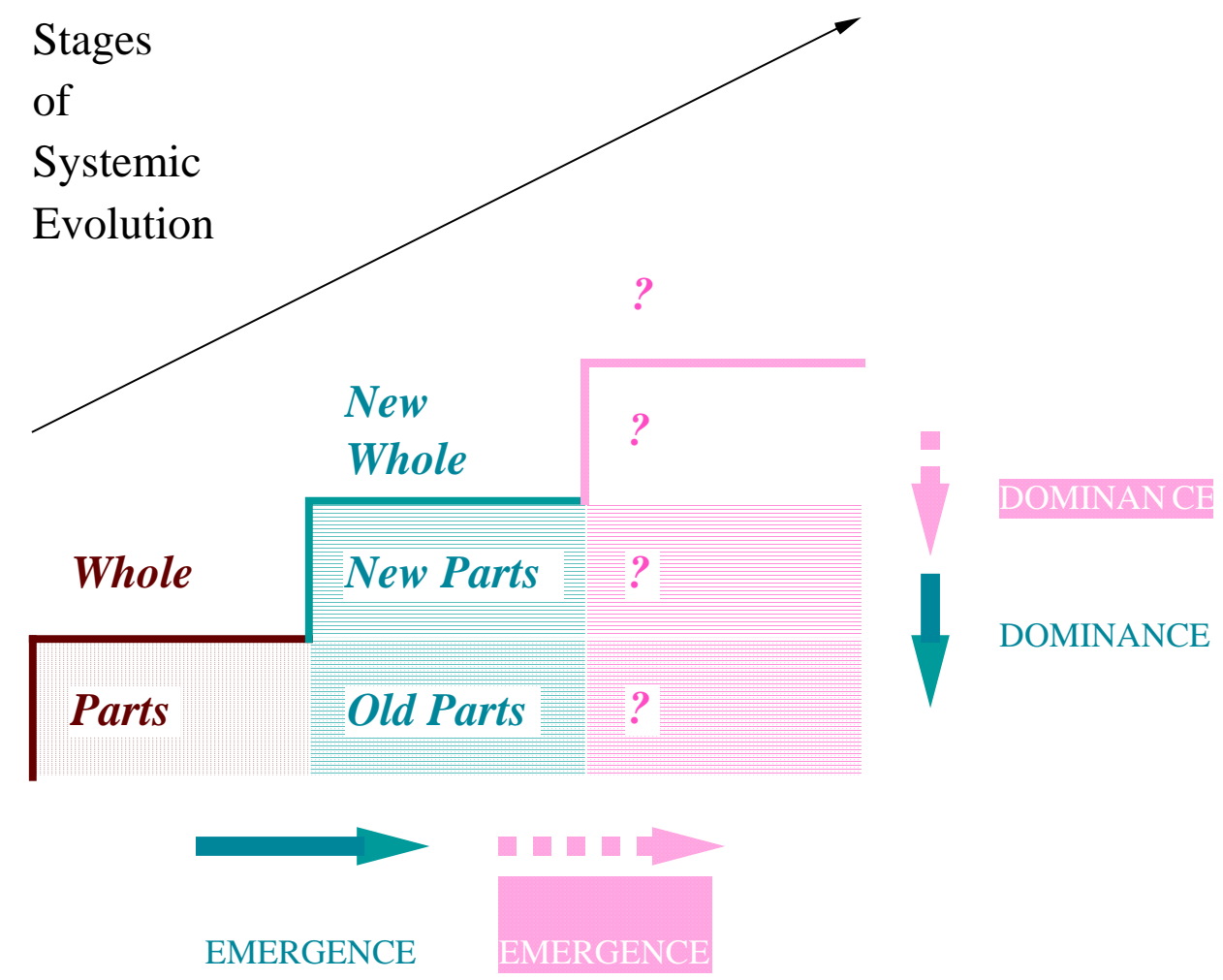

Fig. 3: Stage Concept of Self-organization

Emergence and self-organization are contingent events. That is, a theory of evolutionary systems must rest upon a less than strict determinism. As science unravels the natural world, strict determinism describes systems at or near thermodynamic/chemical equilibrium only. It does not hold for systems exposed to fields in which the uneven distribution of energy flux density exceeds a critical level. Such field 
potentials force energy to flow in a non-linear and interdependent manner. It is here that the systems demonstrate self-organization, i.e. the build-up of order out of fluctuations via dissipation of high-entropic energy as Prigogine (1980) discovered. A touch of indeterminism enters causal relationships that involve self-organizing systems, for the systems themselves select one of the several possible ways to react. Thus, an ontological quality gap remains between cause and effect that cannot be bridged by epistemological prostheses. In strictly determined events, mechanisms are at work that necessitate the transformation of particular causes into particular effects. Here causa aequat effectum or actio est reactio-as Newton's dictum may be applied (Fleissner and Hofkirchner 1997). In events that are not strictly determined, as is the case in self-organizing systems, the effect is not predictable because it is the system that intervenes in the chain of cause and effect and introduces a degree of freedom that cannot be forced into a single alternative. The effect is emergent, it is promoted by the self-organization of the system, and it produces something new--a new entity. Thus, causa non aequat effectum, actio non est reactio. In this case formal science runs short of methods that perform transformations which are not of the one-to-one type. What is needed is reasoning beyond formal reasoning. If the objective relationship seems to be nonmechanical here, i.e. dialectic, then non-formal, i.e. dialectical, reasoning seems to be an adequate intellectual approach (see Hofkirchner 1998). Dialectical reasoning, however, since it does not lead to clear-cut explanations, does not provide clear-cut predictions either.

\section{Emergence and Social Systems}

The rethinking of the central issue in social science-the issue of how agency and structure are to be related in terms of dialectic, emergence and self-organisation--may refer to and integrate important ideas and insights of those recent attempts to overcome the dichotomy in social theory which (with the exception of, e.g. Artigiani, 1991) do not explicitly refer to an evolutionary systems theory of society (e.g. Giddens 1984; Alexander 1995; Mouzelis 1995; Reckwitz 1997). It promises a solution to the problem of how to deal with indeterminacy in the object domain of science.

From the perspective of self-organisation in the framework of evolutionary systems theory (see Figure 4) the self-organisation cycle working in social systems may be conceived of as shown in Figure 5 (for a discussion of how the mutual production of actors and structures conceived as social self-organization is connected to the social theories of Anthony Giddens and Pierre Bourdieu cf. Fuchs 2003a, b).

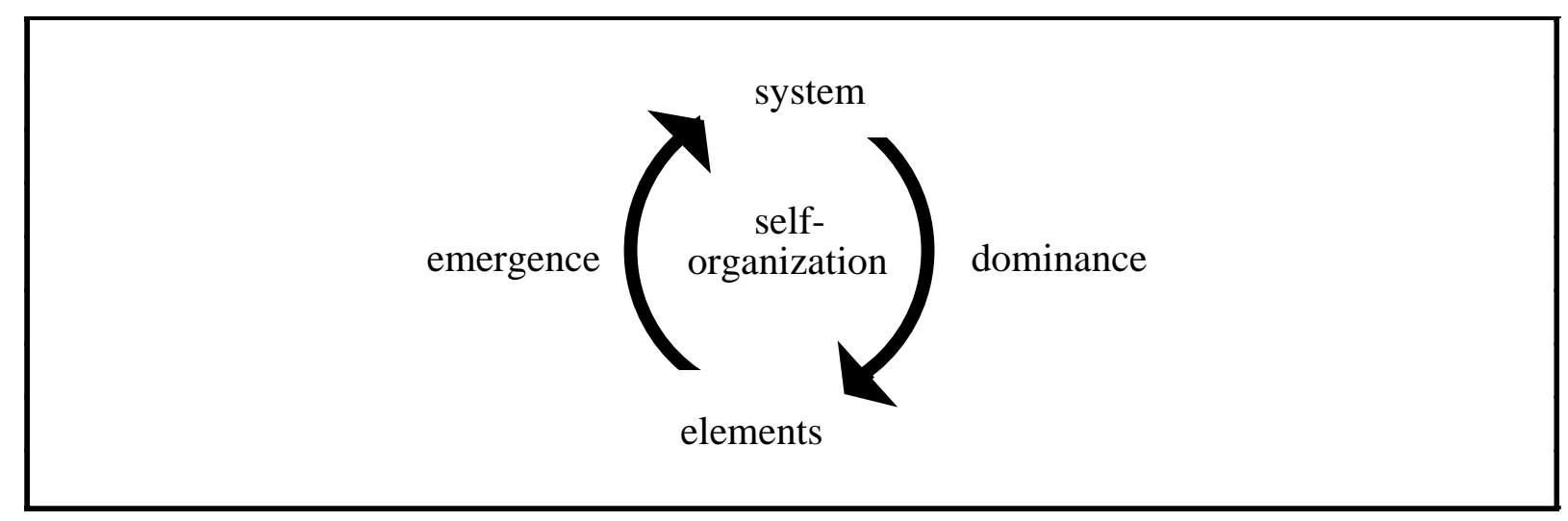

Fig. 4: Self-organization in Evolutionary Systems 


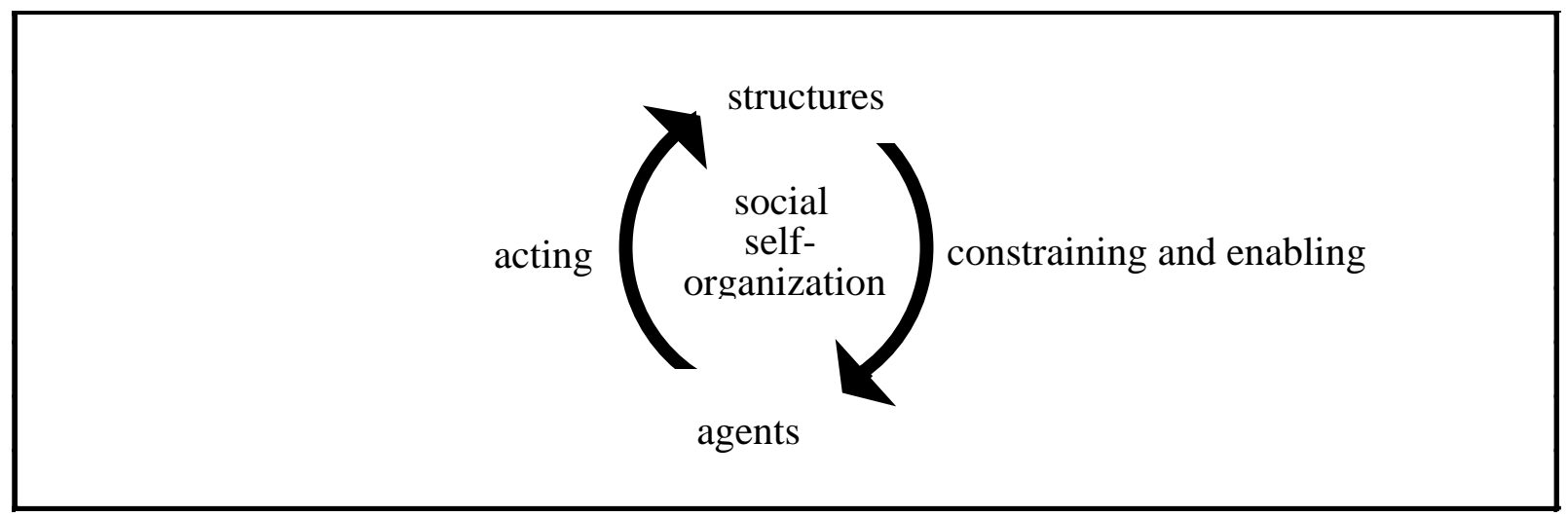

Fig. 5: Self-organization in Social Systems

There are two levels, the micro- and the macro-level. The elements or agents of the system are located at the micro-level. These agents perform actions. The interplay of these recurrent individual actions produce fairly stable relations among the agents These relations gain relative independence from the interactions in the form of regularities which concern allocative and authoritative resources, and in the form of rules or values, ethics and morals. Such structures emerge at the macro-level, where they--insofar as they, in turn, influence the agents--exist in their own right. On the one hand, they constrain the individual agent by setting conditions that limit her scope of action; and, on the other hand, by doing so, they provide her with the potential for realizing options she otherwise wouldn't have. Nor can dominance control the outcome insofar as the structures do not determine directly and therefore cannot determine completely whether or not these options will be realized, since the actions are performed by individual agents. The structures are impressed upon the individual agents by an endless process of socialisation and enculturation. The resulting engrams serve as cognitive tools for the anticipation and construction of ever new actions which may or may not fit regularities and renew allocative and authoritative resources, and which may or may not obey rules and accept values and recognise ethics and follow morals and thus may or may not reproduce the structures. Either way, interaction reflects upon the conditions of its own emergence and may consciously be directed at the structures in order to maintain or alter them. In this sense only--that is, because in their recursive actions the agents refer to the structures--do these structures play the dominant role in the relation of bottom-up and top-down causation. Nevertheless none of the relations in this causal cycle lead to unambiguous results. Each influence--bottom-up as well as topdown--has consequences which due to the inherent indeterminacy cannot be foreseen. In this way and only in this way is qualitative change possible.

As far as the underlying ontological assumptions are concerned, there are, apart from this dialectical view of the relationship between individuals and society, three archetypical perspectives: one that reduces society to (the actions of) individuals, one that projects (system properties of) society onto individuals, and one that dichotomizes society and individuals (see Table 1). 


\begin{tabular}{|c|c|c|}
\hline & \multicolumn{2}{|c|}{ Relationship between } \\
\hline & Individuals... & and Society \\
\hline $\begin{array}{l}\text { INDIVIDUALSM, } \\
\text { AGENCY THEORY, CONSTRUC TIVISM } \\
\text { (BOTTOM-UP DEIERMINISM) }\end{array}$ & suffic ient conditions & resultant \\
\hline $\begin{array}{l}\text { SOCIOLOGISM, } \\
\text { "SYSTEM THEORY," } \\
\text { STRUCTURAUSM } \\
\text { (TOP-DOWN DETERMINISM) }\end{array}$ & resultant & suffic ient c ond itions \\
\hline $\begin{array}{l}\text { INDIVIDUAL-SOCIETY DUALSM } \\
\text { (INDEIERMINISM) }\end{array}$ & \multicolumn{2}{|l|}{ independent } \\
\hline \multirow[t]{2}{*}{$\begin{array}{l}\text { INDIVIDUAL-SOCIETY DIALECTICS } \\
\text { (BOTIOM-UP ASWELAS } \\
\text { TOP-DOWN EMERG ENTISM) }\end{array}$} & $\begin{array}{l}\text { necessary, } \\
\text { but not suffic ient } \\
\text { conditions }\end{array}$ & emergent \\
\hline & emergent & $\begin{array}{l}\text { necessary, } \\
\text { but not suffic ient } \\
\text { conditions }\end{array}$ \\
\hline
\end{tabular}

Tab. 1: Ways of Relating Individuals and Society

\section{The Generation of Information in Social Systems}

\subsection{The Individual in Modern Society}

The concept of the individual as we know it today arose with the emergence of modern, i.e. capitalist society. This concept is related to ideas, such as that of free will and of subjects that act rationally and responsibly, that were developed during the course of the enlightenment. The enlightenment was an integral element of the process establishing modern society. The concept of the modern individual is also one which has been made possible by casting doubt on religious eschatologies which postulated an unalterable and god-given fate for mankind. The rise of this modern notion of the individual has also been related to the rise of the idea of free entrepreneurship in a free market society. Freedom has been conceived in this sense as an important quality and the essence of the modern individual. The idea of the modern individual can be seen as a logical consequence of liberal capitalism. According to this concept, morally responsible and autonomous personalities flourish in the economic and political freedom guaranteed by modern society. It also stresses that society guarantees individualism by removing obstacles to individual freedom, as well as rational and reasonable behaviour. In modern society, individualism is characterized by the pursuit of economic self-interest. Egoism and selfishness are often fetishised by assuming that they are natural characteristics of all individuals and products of rational and autonomous thinking. But it can also be argued that our modern society is not rational because it does not guarantee happiness and satisfaction to all human beings, in fact these characteristics can only be achieved by a small privileged elite.

Nowadays individuals are not only considered to possess free will, it is also generally assumed that free will can be exercised in order to gain possession of material resources and capital in order to realize 
individual freedom. So freedom is seen as something that can be achieved by striving for individual control of material resources. This shows that the concept of the modern individual is inseparably tied to the idea of private property. The idea of the individual as property owner has dominated the philosophical tradition from Hobbes to Hegel and still dominates philosophical thinking about the essence of mankind. But this concept could never be applied to all human beeings in our society because the majority of the world population still does not participate in all these idealistic aspects of freedom and autonomy, this majority is rather confronted with the disciplinary mechanisms of compulsions, coercion and domination that have been considered typical of capitalist society by Foucault and others (see e.g. Foucault 1976). Hence the modern idea of the individual can be seen as an ideology that helps to legitimize modern society. The idea of the individual as a naturally autonomous being may be an agreeable ideal, but today it must still be regarded as nothing more than the product of imagination and self-deception.

\subsection{Constructivism, Structuralism or Interactive Dualism}

When explaining how the consciousness of an individual emerges, one must recognize clearly that individuals are social beings and that they can only exist as participants in social relationships. On the other hand, society is not possible without individual actors who relate their behaviour to that of other actors. The question of how consciousness emerges is a question that is closely connected to the question of how being and consciousness are interrelated. In fact, Friedrich Engels said that the basic question of philosophy concerns this relationship of being and consciousness: "The great basic question of all philosophy, especially of more recent philosophy, is that concerning the relation of thinking and being" (Engels 1886: 274). Engels used the term reflection to describe the materialist argument that being determines or dominates consciousness, but he did not work out an epistemological framework. Nonetheless he asked some basic questions that still are very important for epistemology today: "In what relation do our thoughts about the world surrounding us stand to this world itself? Is our thinking capable of the cognition of the real world? Are we able in our ideas and notions of the real world to produce a correct reflection of reality?" (Engels 1886: 275).

According to the view of the relationship between individuals and society shown in Table 1, there have traditionally been three different positions in relating the categories of thinking and being, well-known today under the labels constructivism, structuralism and interactive dualism.

An epistemological tradition that concerned itself with this question is formed by the types of epistemological constructivism represented e.g. by Humberto Maturana, Francisco Varela, Heinz von Foerster, Ernst von Glasersfeld and Paul Watzlawick. Constructivist approaches share the view that cognition is constructed in an autonomous manner and is not determined by social/ physical reality. Maturana and Varela (1984) have put forward the idea of living systems as autopoietic ones that can reproduce and maintain themselves and they have laid the groundwork for Radical Constructivism in epistemology by describing the brain as structurally coupled to its environment. By structural coupling they mean that the brain works in such a way that the environment, i.e. society, can not determine cognition, it can only perturbate structural changes in consciousness. Maturana and Varela conclude that consciousness can be developed relatively autonomously from society, that reality is always a subjective construction and that there is no objective reality. Maturana criticises that traditionally scientific, religious, ideological and political institutions and movements have said that they can objectively claim what is true in order to legitimize existing power-structures (see Maturana 1988). Maturana and Varela say that the brain works autopoietically in such a way that a particular condition of the neurones leads to the next one. Hence it can reproduce itself and cognition, and consciousness emerges.

Constructivism can be seen as a reductionist conception that does not consider the dialectical relationship of the individual/consciousness and society/being. It does not take into account the limitation and structuration of individual action, and the thinking in social relationships. If reality, cognition, and 
consciousness are solely seen as autonomous constructions, existing social pressures, coercion, domination, and manipulation are not sufficiently taken into account.

Structuralism conceives the relationship of being and consciousness in a structuralist manner by assuming that being determines consciousness. Particularly Structuralist Marxism and the theory of reflection, which can be seen as a type of Marxist epistemology, have influenced such assumptions considerably. For example, Lenin already assumed that the economic basis of society determines the superstructure and that economic structures are reflected in philosophy, religion, politics and individual consciousness.

The Frankfurt School also conceived this relationship in a structuralist manner. One of their main theses was that capitalist society manipulates individual consciousness in such a way that members of society identify themselves more and more with society. In this respect they particularly stressed ideological mechanisms of manipulation that can be found in aspects of mass culture and cultural industry. Horkheimer and Adorno (1972) analysed the mechanisms of the cultural industry and concluded that it is a mechanisms designed to keep the masses in a state of helplessness: "The culture industry as a whole has molded men as a type unfailingly reproduced in every product. All the agents of this process, from the producer to the women's clubs, take good care that the simple reproduction of this mental state is not nuanced or extended in any way. [...] Pleasure always means not to think about anything, to forget suffering even where it is shown. Basically it is helplessness. It is flight; not, as is asserted, flight from a wretched reality, but from the last remaining thought of resistance" (Horkheimer/Adorno 1972).

Theodor W. Adorno particularly, saw the possibility of society being transformed by self-conscious individuals very pessimistically: "Human beings would be required in order to change the stiff conditions, but those have carried themselves so deep into the human beings - at the expense of their lives and their individuation -, that they hardly seem to be able to develop the spontaneity on which everything would depend" (Adorno 1970: 147). Adorno stated that human beings can not be seen as individuals in capitalist society because an individual would be able to decide for herself and she would possess selfconsciousness. In capitalism, Adorno does not consider human beings to possess self-consciousness. He says that people are, rather, estranged from themselves--that they are not themselves but others. He says that in modern industrial society, human beings are persons, not individuals.

To describe the being of a person in modern society, Adorno uses Marx's concept of the character mask. ${ }^{1} \mathrm{He}$ says that there are no individuals in modern society, only persons that fulfil specific functions and roles in capitalism. The human being as a person is seen "as a moment of the relationships, in which he lives, before he might be able to determine himself" (Adorno 1956: 42). "The fixing of the human as person implies that within the social relationships in which he lives, he always finds himself in specific roles next to others. By them he is what he is in relationship to others: the child of a mother, the pupil of a teacher, the member of a tribe, the bearer of a profession" (Adorno 1956: 43). Character or social masks that have traditionally been seen as typically in capitalist society according to Marxist theory are the capitalist who is forced by economic structures to act in a way that guarantees the endless process of

\footnotetext{
${ }^{1}$ In translating Marx to English, the German word Charaktermaske was not translated directly, so there is no English term for it in the English editions of Marx's writings. But if you look up the parts where Marx used the term in the English editions, it is also clear what he meant by this term. E.g.: "No matter, then, what we may think of the parts played by the different classes of people themselves in this society, the social relations between individuals in the performance of their labour, appear at all events as their own mutual personal relations, and are not disguised under the shape of social relations between the products of labour" (Marx 1867: 91f). Or: "In the course of our investigation we shall find, in general, that the characters who appear on the economic stage are but the personifications of the economic relations that exist between them" (Marx 1867: 100).
} 
capital accumulation and self-expansion of capital as well as the workers who are forced to sell the only commodity they have-their working power-on the labour market in order to survive.

If the theoretical problem of relating being and consciousness is solely approached in a structuralist manner, the dialectical relationship of society and the individual is not sufficiently considered. Individual actions and consciousness are not only being structured by society, they are also a basis for social change that comes about by individuals socially relating their actions and thinking. Orthodox structuralism today seems to be a mechanistic method for solving the problem of how being and consciousness are related.

A third way of approaching the micro-macro relationship of consciousness is in the tradition of what is labelled "interactive dualism." Unlike the mainstream of mind-body philosophy, Popper draws a distinction between objective knowledge and subjective knowledge (Popper 1972). He considers subjective knowledge to be that which exists in each of us, and is related to the individual person and his/her particular experiences and intellectual abilities. Objective knowledge, on the other hand, means to Popper knowledge on a super-personal level, which is still developed from an individual's background, but then acquires an independent existence and exists separately from the person. It develops further and then turns the tables, dictating the nature of the personal knowledge from which it arose. Understanding means nothing more than adopting super-personal knowledge for oneself, or taking down wisdom from a higher level for one's own use. Popper never tired of saying that objective knowledge has a characteristic that subjective knowledge lacks: in his view, a new theoretical discovery trails a whole tail of related problems behind it, which only gradually become apparent to us, and which we may never fully appreciate.

Popper's objective knowledge belongs to World 3, and his subjective knowledge to World 2 of his threeworld conception. The physical constituents make up World 1 . Worlds 1 and 3 are connected only via World 2. Popper noted an upward causation and a downward causation, thus creating both an evolutionary theory and a layer theory. With the help of upward causation, the creation of the world can be imagined genetically, as the world of physical objects, including living organisms (World 1), which brought about the world of sentience and self-awareness, as well as that of the awareness of death (World 2), which in turn led to the world of the products of human thought: language, artefacts, science and technology (World 3). These worlds are built up as layers, one on top of the other, marked by downward causation.

However, the question may be asked as to whether the cosmos can be divided into the three parts Popper envisaged; apart from this, the inconsistency between World 3 as a human creation and World 3 as the permanent home of the intelligibilia, cannot be overlooked. An analogous inconsistency holds for the relation between Worlds 1 and 2. As a result of this inconsistency, he does not offer any resistance to the view that souls exist and that God's work is involved in the downward causation; in fact he wrote a book with a proponent of such a theory, the Catholic Eccles (Popper/Eccles1977). His theory thus displays a dualistic shortfall. It differs in one aspect from traditional dualism, which postulates the separate existence of entities, his dualism of interactionism, i.e. the possibility for the entities to mutually influence each other.

The problem of relating thinking and being can not be solved completely by constructivist, structuralist or dualistic approaches. A solution that takes into account both the effects that society has on the individual and those that the individual has on society can be achieved by a dialectical and emergentist approach that brings together the concepts of information and self-organisation. 


\subsection{A Dialectical and Emergentist View}

\subsubsection{Individual Information}

The problem of relating being and individual consciousness can be resolved dialectically by assuming that consciousness is neither solely an individual construction nor solely a reflection of society. We argue that cognition has an objective as well as a subjective character. On the one hand, individuals transform society by acting consciously, on the other hand social structures influence consciousness. Contrary to orthodox forms of Structuralist Marxism, Marx himself already stressed the dialectical relationship of being and action/consciousness. Whereas Engels rather liked to talk about objective economic laws that determine the course of history in a linear fashion, Marx often pointed out that society can and should be transformed by self-conscious and critically thinking/acting subjects. On the one hand he clearly saw that individuals are objects of the structural categories of capitalism and that their thinking is being influenced by these structures, but on the other hand, he also stressed that these structures must be changed by subjects who become self-conscious in order to transform society and transcend capitalism. In his Theses on Feuerbach, Marx outlined this dialectical relationship of being and consciousness/action: "The materialist doctrine concerning the changing of circumstances and upbringing forgets that circumstances are changed by men .... [T]he human essence ... is the ensemble of the social relations .... The philosophers have only interpreted the world, in various ways; the point is to change it" (Marx 1845, Theses on Feuerbach).

Marx summarized this dialectical relationship of structure and action, e.g. in a famous passage from "The Eighteenth Brumaire of Louis Bonaparte": "Men make their own history, but they do not make it as they please; they do not make it under self-selected circumstances, but under circumstances existing already, given and transmitted from the past" (Marx 1852: 115).

Herbert Marcuse, just as Horkheimer and Adorno a representative of the Frankfurt School, also conceived the relationship of being and consciousness/action dialectically. Concerning the emergence of critical consciousness and self-conscious subjects that are able to radically transform society, he was much more optimistic than Adorno. Like Adorno he stressed, on the one hand, that ideological mechanisms manipulate individual consciousness (see e.g. Marcuse 1967), that control which is exercised by society is introjected into individual consciousness, and that this results in the direct identification of the individual with society as a whole (what he termed mimesis, see Marcuse 1967: 30). But on the other hand he also pointed out that society, nonetheless, can be transformed by new, i.e. selfconscious and critical individuals, in such a way that a new society emerges in which the happiness of mankind can be achieved, in which penury and famine can be overcome, and a maximum of free time realized by making use of modern technologies and by developing the forces of productivity in an ecologically and socially sustaining manner. Especially the emergence of the revolutionary movements of 68 convinced Marcuse that a sustainable humanising transformation of society would be possible and that a new subject of transformation was about to emerge (see e.g. Marcuse 1969). Although basic social change may seem impossible today, and although the new movements of social change have been institutionalised in many ways, there is no need to be pessimistic about the possibilities of social change. In fact, it is necessary and realistic to remain as optimistic as Marcuse: "[The rebels of 68] have revoked the idea of revolution from the continuum of oppression and connected it with its true dimension-the one of liberation" (Marcuse 1969: 243). The liberation of the individual and of society is still possible, and it is still necessary.

We think that the emergence of individual consciousness can be best explained dialectically in the framework of a theory of self-organization and evolutionary systems. A yet-to-be-developed Unified Theory of Information (see e.g. Fenzl/Hofkirchner/Stockinger 1998, Hofkirchner 1999b) that is based on 
the theory of self-organisation seems to be able to explain the emergence of individual and social information in a dialectical manner. We now want to point out some basic assumptions and theses that could form initial elements of such a unified theory (for further and more detailed explanations see Hofkirchner 2000, Fuchs 2000, 2001).

In social systems individual values, norms, conclusions, rules, opinions, ideas, and believes can be seen as individual information. Individual information does not have a static character, it changes dynamically. Individual opinions and values, for example, change permanently because of new experiences. This does not mean that individual information is necessarily always unstable and that the reflection of ideologies in individual information, for example, does not exist. Instead, new experiences enhance and consolidate existing opinions, but they can also radically change them. Hence it can be said that individual information as a lower level of information in social systems has an unstable character. When we reach higher levels (as we will see in the case of social information that is constituted in social relationships), the complexity as well as the stability of the information increases. The higher level phenomenon plays the role of the order parameter vis-à-vis the lower level phenomenon. The constitution and differentiation of individual information can be described as follows (see Figure 6 as well as Hofkirchner 1999a):

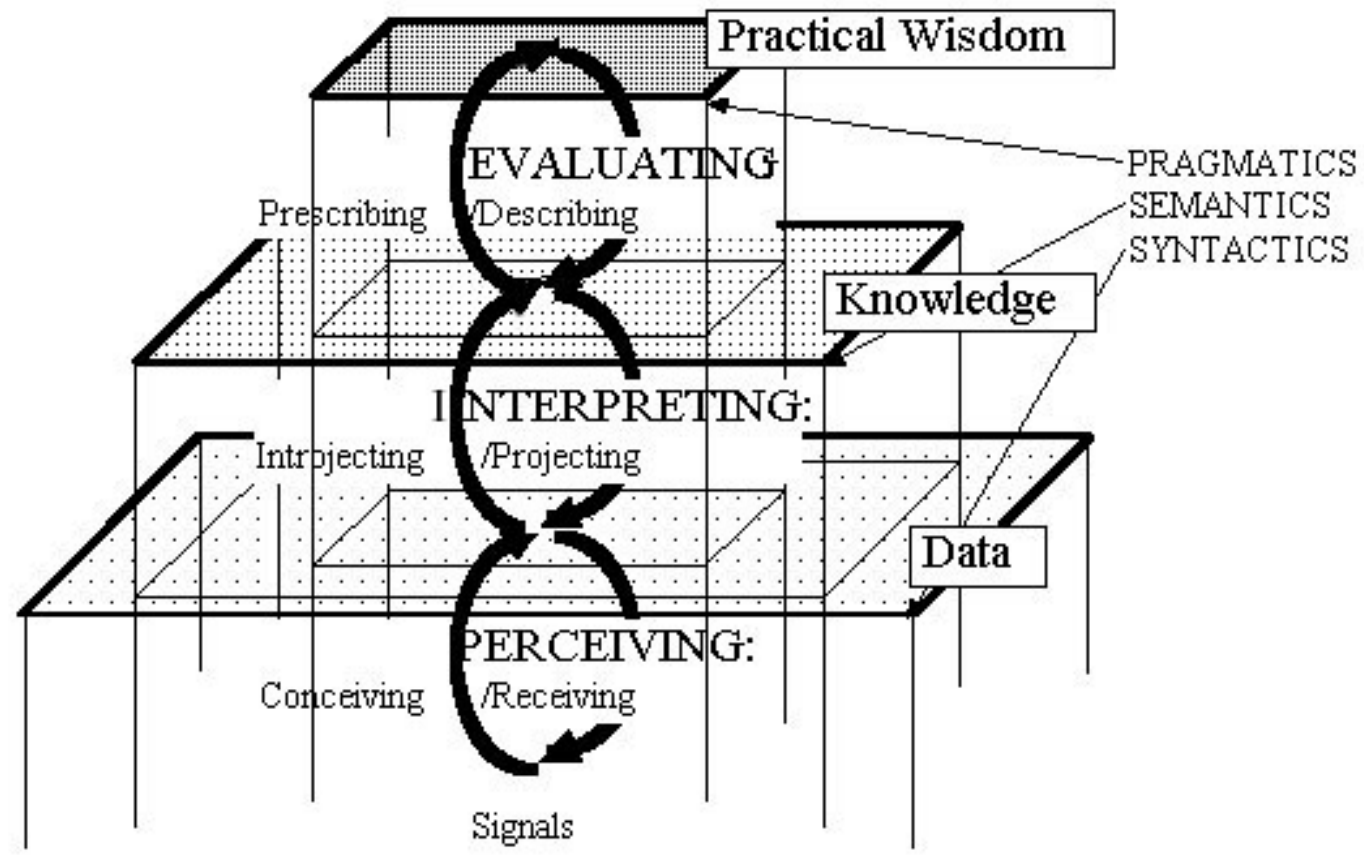

Fig. 6.: The generation and differentiation of individual information (see Hofkirchner 1999a)

Cognition is always bound up with the outside world, a subject relates itself to events and states of its environment. The informational happening can be described as layered; levels of higher and lower quality can be distinguished. A transformation of information from lower to higher levels takes place. The generation of individual information starts with the reception of signals from the environment. The update of the signals starts with a particular state of experience of the cognitive system. Receiving applies to the uptake of signals which come from the perceivable environment. Conceiving is dedicated to the registration and bringing together of the signals to a "view" of some aspects of the environment. Perception unites conception and reception: it is an unceasing movement, an oscillation between reception and conception. An act of perception involves the reception of signals and the conception of impressions, i.e. a new whole that is called data. Perception is a process that reflects and potentially changes the current cognitive structure. The emerging structure is the starting point of the next 
perception. The whole can acquire a new emerging quality which the previous one did not have. Thus, on the first level, signals are made into data by perception, an act that involves reception and conception.

On the next level, the data is interpreted; meaning is given to the data. Thus knowledge is formed. The process of interpretation involves the interplay of projection and introjection. It starts with a certain state of interpretation/knowledge, which is the basis for the emergence of new knowledge. Projection means that first the system projects its cognitive structures onto reality, i.e. the current state of knowledge is applied to the data. Introjection means that the data can be interpreted in such a way that the structure of knowledge changes-new knowledge emerges. The system has introjected reality into its structure. New areas of reality, new experiences have been brought into the system. As on the first level reception and conception, there are two opposing processes: projection and introjection. They form part of the motor of the endless movement of cognition.

Here the question raises itself whether knowledge is constructed relatively autonomously from the environment in order that data as perceived signals from the outside can only perturbate but never determine changes in the cognitive knowledge-structure or whether knowledge as a representation corresponds to the environment of the cognitive system. It can be said that the environment can never determine cognition entirely, knowledge, is, however, also not wholly autonomously constructed without reference to the environment. Arguing dialectically, we can say that reflection and construction require and contradict each other. The formation of knowledge as the interpretation of data involves projection as an element of construction as it does introjection as an element of reflection. Knowledge as the result of interpreted data can be seen as the level which involves experiences and facts.

On the third level, knowledge is evaluated and sense is made of it. Individual information such as values, norms, rules, opinions, ideas, and believes is created by the fact that the subject puts its knowledge into the context of its goals. This action is seen as evaluation, which is made up of the elements of description and prescription. The process starts with the current state of individual information in a particular situation where an individual must act in order to solve a problem. Description means that on the basis of the current individual information structure the individual is looking for solutions. The situation and the solutions refer to the knowledge at the lower level, which represents facts and laws. In the prescriptive phase a decision is made about the implementation of a solution. A solution considered good, beautiful, and just is selected. At this upper level the process of cognition cumulates to practical wisdom which is seen as individual information that allows an individual to create situations that he/she experiences as good, beautiful, and just. The existence of individual wisdom does not necessarily mean that the decisions taken by individuals are socially wise ones.

When problems are solved by evaluating knowledge, and by acting on the basis of experience, facts (knowledge) and the current individual information in order to select a good solution to a problem, new individual information may emerge. This is neither a necessity nor an impossibility. It is impossible that we act and try to find solutions without enhancing and changing our individual values and norms. In fact, this is the case in most of our actions. In such a case individual information remains unchanged. But in other situations it might be different, new individual values, norms, rules, opinions, or believes emerge on the basis of new experiences when we perceive signals from the environment as data, interpret the data as knowledge and establish new individual values, norms, opinions, and believes by acting and making decisions on the basis of knowledge and the current individual information structure.

The signals on the lowest level can refer to trivial objects in our daily life such as a flower, but the object of reference can also be social information which is constituted in social relationships. This establishes a relationship between individual and social information. When a sign is considered to be the product of an information process, data, knowledge, and wisdom can be regarded as the three types of interrelated signs that appear in the process of formation and differentiation of individual information. 


\subsubsection{Social Information}

We have to distinguish between different levels of self-organisation, i.e. self-organisation has aspects that are common to all types of systems as well as aspects that are particular to each concrete type of system. So self-organisation is related to a dialectic of difference and identity.

In physicochemical systems, self-organisation means the spontaneous emergence of order in a system that is far from its thermal equilibrium. If a certain threshold of a specific control parameter is crossed, fluctuations intensify and order emerges. The Bénard convection-cells are an example. This process of self-organisation in physicochemical systems is based upon dissipation because low-entropic energy is imported from the environment of the system and high-entropic energy is exported from the system. This enables the system to gain order, energy carrying high entropy is dissipated.

In living systems, self-organisation refers to the autopoiesis of such systems. That is, they can maintain themselves by reproducing their parts and hence the unity of the system permanently. An autopoietic system can maintain and reproduce itself and it can set up its own borders. All living systems are autopoietic ones. Autopoiesis functions on the basis of dissipation.

In a social system, self-organisation refers to the so-called re-creation of such a system. Re-creation means that social systems do not only have the capacity to modify themselves (as dissipative systems do) and to maintain themselves (as autopoietic systems do), but they also have the capacity to re-invent themselves, to shape themselves, to produce a specific character by which the individuals that are parts of a social system can strive to realize themselves in a more or less self-determined way.

A sign, then, can be seen as the product of an information process. An information process occurs whenever a system organises itself, that is, whenever a novel system emerges or a qualitative novelty emerges in the structure, state, or behaviour of a given system. In such a case information is produced. It is embodied in the system and it may then be called a sign.

Pattern formation in dissipative systems is the most rudimentary way to form signs. A stimulus from the system's environment is reflected by its activity and a pattern is formed. This can be seen as the production of signs on a protosemiotic level. In autopoietic or living systems, responses are no longer simple patterns. Instead they become something with the attribute of an activity-oriented meaning for the system in question. This something shall be called a proxy. Thus sign production at this stage of evolution turns from pattern formation to the formation of proxies, that is, as far as cognition is concerned, sensations and motivations. On this level of self-organisation, the information that emerges has parasyntactic as well as para-semantic pragmatic aspects. In re-creative, i.e. social, systems which have the capacity to transcend themselves signs appear as, so to say, "not-yets". On this level self-organisation produces not only individual information as cognition with full-fledged threefold semiotic dimensions but also what can be termed social information of which individual information is part of: The word "social" in the term social information denotes that such a form of information is constituted in the course of social relationships between several individuals. According to Max Weber a social relationship is established if an interrelated reference exists between two actors. Social acting is orientated around meaningful actions of other actors. Social actions are a necessary condition of a social relationship, but not a sufficient one because social acting doesn't necessarily require the actors to mutually refer to each others actions: One actor can refer to the actions of another without the latter referring to those of the first.

We consider the scientific-technological infrastructure, the system of life-support elements in the natural environment and all else that makes sense in a society, i.e. economic dispositions, political decisions, and the body of cultural definitions like norms and values, laws and rules (the latter do not need to be codified, 
they can also be established in the form of traditions or habits) to be social information. All of them are constituted in the course of social actions. Individuals must have a common view of reality which is the basis for their social interactions and social actions. They are elements of a social system. As a result of their interactions in social systems, social information emerges as a macroscopic structure. Acts of cooperation are mediated by acts of communication which, in turn, are mediated by acts of cognition. Individuals act in such a way that they trigger associations and actions of other individuals. Individuals coordinate their actions in such a manner that they produce a common social information structure.

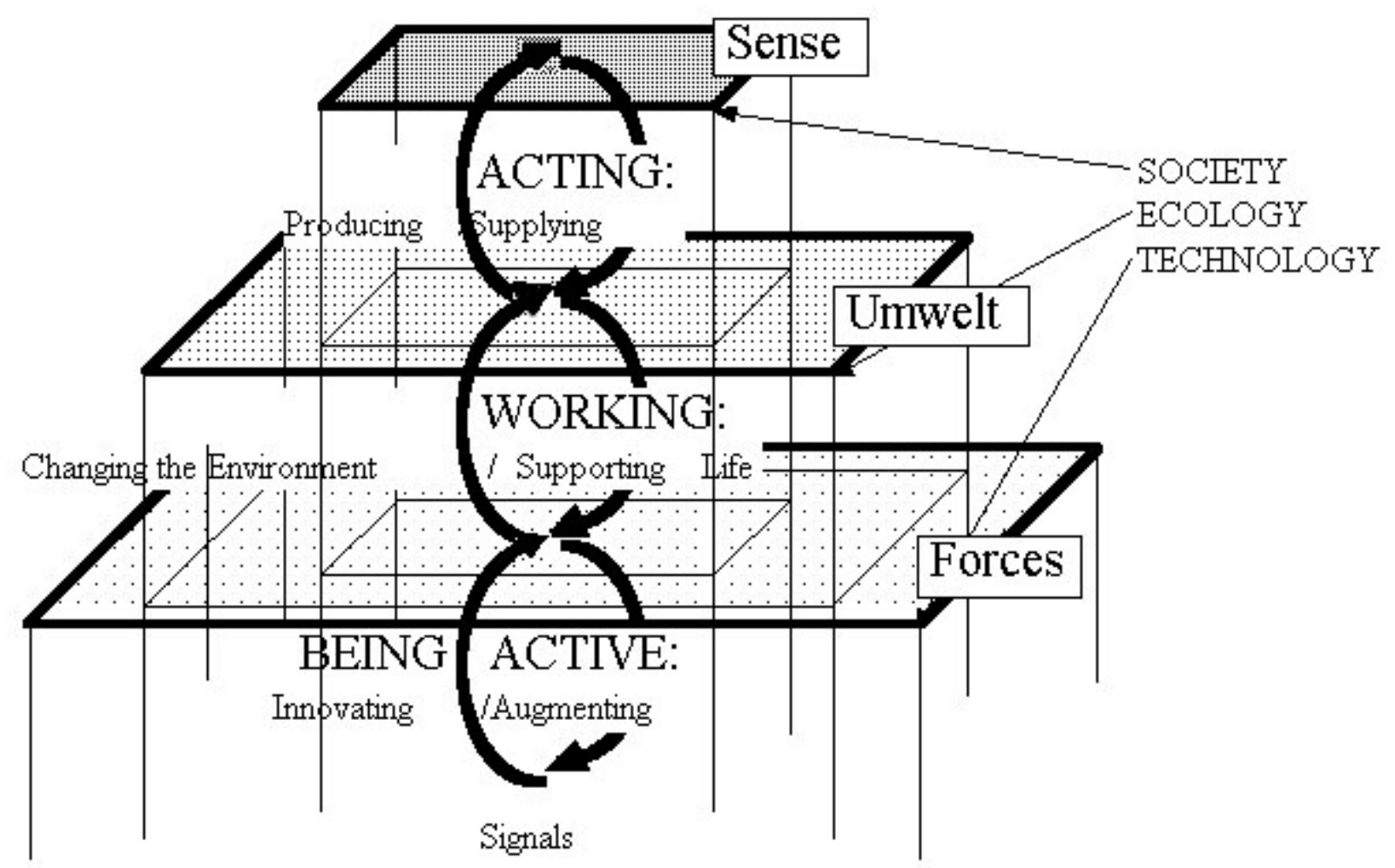

Fig. 7: The generation and differentiation of social information, part I

At a first glance (see Figure 7), you can distinguish three main spheres that form the layers of hierarchical social systems: the technosphere is dominated by the ecosphere and the ecosphere by the sociosphere. The technosphere is the sphere in which human beings are active in innovating and applying scientific-technological tools in the course of social life. An infrastructure of tools, methods and capabilities which comprise the overall forces of the socially living humans is the base of re-creative systems and at the same time the simplest quality of social information. The ecosphere is the sphere in which human beings work, in other words, where they use their tools, methods and capabilities to adapt nature to themselves in order to survive and construct an umwelt, where they objectify the life-support conditions of nature and appropriate nature to assure them of life support. The natural environment in its character of providing life support is another product of re-creative systems and another quality of social information. The sociosphere as a whole is the sphere in which human beings perform social actions. Here they constitute what makes sense to them and realize it. Sense is then another of the higher qualities brought forth by the re-creation of social systems and social information. In fact, it is the result that constitutes the differentia specifica to nonhuman biotic, simple autopoietic systems.

Upon closer scrutiny, the constitution and realization of sense can be differentiated further. Usually economy, politics and culture are the realms in which sense is produced by social actions. 
In his theory of structuration, Anthony Giddens (1997) describes rules and resources as structures that are both medium and result of social actions (Giddens 1997: 77). He further distinguishes between allocative and authoritative resources. The former relate to abilities that make the domination over objects, goods and material phenomena possible. The latter concern the generation of domination over individuals and actors (p. 86). Concerning the institutions of society, Giddens says that symbolic orders, forms of discourse, and legal institutions are concerned with the constitution of rules, political institutions deal with authoritative resources and economic institutions are concerned with allocative resources.

Today power is distributed asymmetrically in the areas of economy, politics and culture, but a wise society that would be socially, ecologically and technologically sustainable would have to progress towards a symmetrical distribution of power. Domination in contrast to power can not be distributed, but it can be overcome.

Our own model of society makes use of Giddens's distinctions. It is a general one that does not only cover modern capitalist societies and tries to avoid a naturalisation of relationships of domination/exploitation/class. Hence it should have a dialectical character: On one level it must be general enough in order to explain all possible types of societies, on the other there must be specific levels and concretizations that help to explain specific formations of society (such as capitalism) and different phases of these formations.

The model outlined here is a general one. It is possible to go one step further in order to describe our modern society as a capitalist one. On a third level, concrete modes of development can be distinguished which describe the different phases of capitalism that we have been experiencing. Currently we live in a post-fordist, neo-liberal and info-societal mode of development of capitalism (see Fuchs 2001).

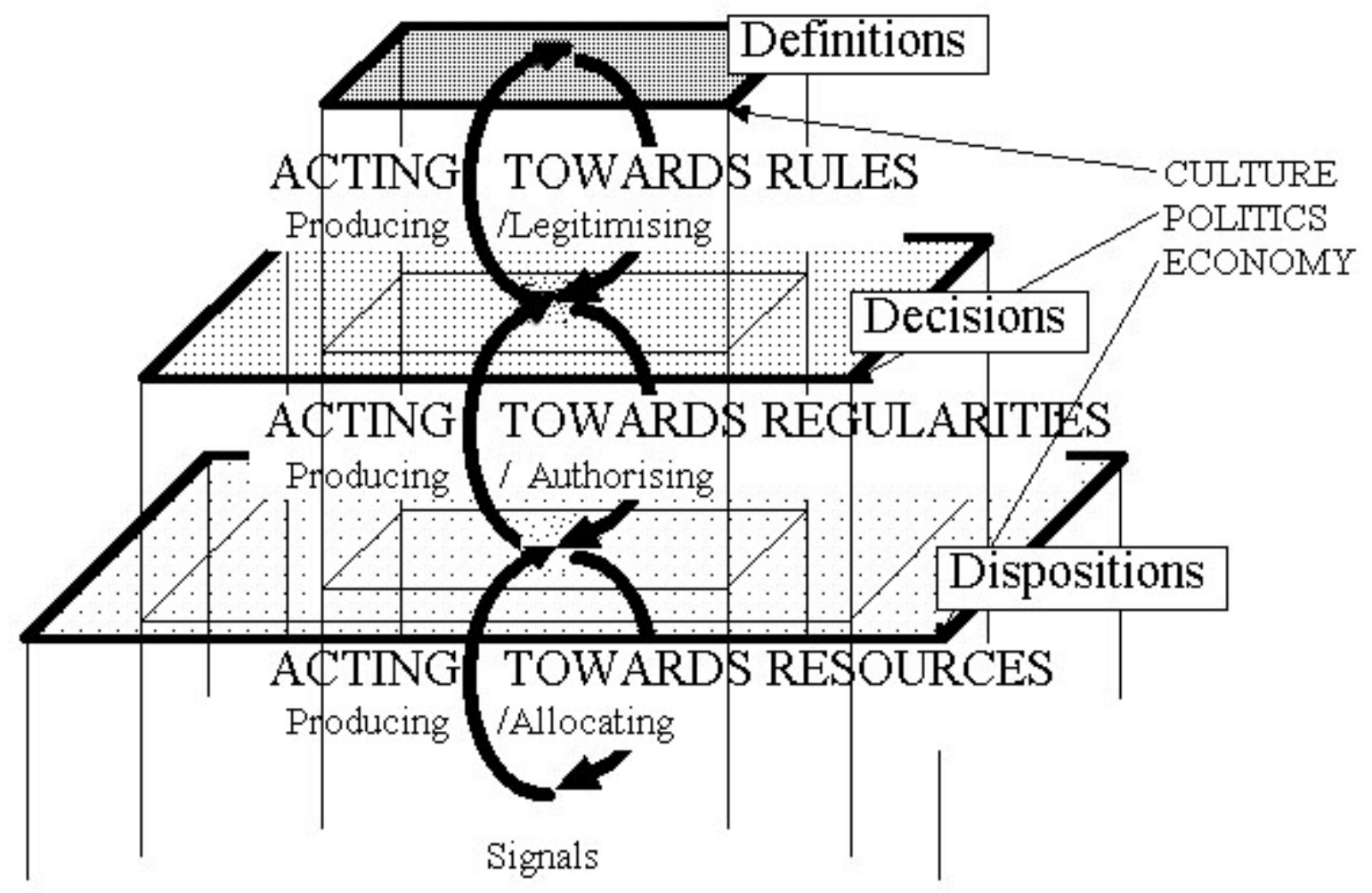

Fig. 8: The generation and differentiation of social information, part II

In short, in all social systems there are three manifestations of information (see Figure 8): dispositions over resources, decisions on life conditions that form regularities of the living together and definitions of 
rules like norms/values. They store information about past social actions and simplify future social situations because by referring to social information the basics of acting socially do not have to be formed in every situation of this kind. Social information serves as a durable foundation for social actions, even though it changes dynamically.

It can be found in all subsystems of society-economy, politics and culture.

Economy deals with the production, distribution and allocation of use values and resources. The basics of each economic process are formed by productive forces which combine the living labour force system, that is, physical ability, qualification, knowledge, abilities, experience, as well as technology, science, amount and efficacy of the means of production, and organisational factors, with natural ones that are due to the umwelt. The disposition of resources which appear as property relations can be seen as social information on the economic level. Economy means a dual process of production and allocation. Material resources that are vital to society are produced by making use of the system of productive forces. On the other hand, resources are utilised in order to ensure the preservation of the members of society in a process of allocation of economic goods.

Production and reproduction can be seen as the material basis of each type of society. Such a materialist view is not a reductive one if one considers that though the political and cultural superstructures depend on economic processes they work nevertheless in relative autonomous ways and influence economy in processes of downward causation as well. All of them are dialectically related because economic influences on politics and culture can cause the emergence of new political and cultural phenomena, and cultural and political influences on economy can cause the emergence of new economic phenomena.

Politics deals with decisions which refer to the way life conditions are set (including how economic resources are being used and how they are distributed). The decisions that are being reached in a social and communicative way in the area of politics turn out to be just another type of social information. Politics encompasses a dual process of decision-making and authorisation of actions: Decisions are made on the basis of available resources in order to assure the functioning of society. These decisions either take on coded or non-coded forms. Once a decision is reached the next step is to execute it. And executing decisions always means that members of the society are authorised to act in a particular manner.

Culture can be seen as the subsystem of society in which ideas, views, social norms, and social values are defined within the framework of habits, ways of life, traditions, and social practice. The emerging social rules are a type of social information that comes into existence in the area of culture. Culture encompasses a dual process of defining the rules and being legitimised by observing the rules. On the one hand social norms, values, ethics and morals are constituted and differentiated in relation to decisions already reached. On the other hand, social norms legitimise acts of the members of society. The type of participation determines if at all, how, and to which degree individual actors and social groups can influence rule definitions which affect them.

Neither culture, nor politics are fully determined by economic processes. Each subsystem enjoys relative autonomy, nonetheless, in modern capitalist societies economic processes dominate. In the area of culture we follow among others the view that stands in the tradition of the Cultural Materialism of Raymond Williams (1961), which has had tremendous influence on the whole area of Cultural Studies. Williams argues that culture includes the "whole way of life" (Williams 1961: 122), including collective ideas, institutions, descriptions by which society reflects experiences and makes sense of them, and ways and traditions of acting and thinking, and intentions that result from it. Williams further stresses that culture involves the formation of values as social categories. Edward P. Thompson took up Williams' theory of culture and added the idea that the whole way of life and experience is influenced by class struggles and social conflicts. 
Williams and Thompson argued that culture is neither independent from political and economic processes, nor can it be reduced to these areas. Already Antonio Gramsci stressed that superstructures cannot be reduced to the economic base (Gramsci 1930/31a) and that culture involves the "creation of (new) world-outlooks" (Gramsci 1930/31b) and morals of life (Gramsci 1934). Materialistic theory that deals with culture has always stressed cultural information, its relative autonomy and its relationship to socio-economic processes, only vulgar forms of materialism reduce culture or politics to economics. Culture as the top level in our hierarchy depends upon economy and politics, it forms the integral whole of social life that includes the areas and ways of life that we find in ideational and material reproduction (Marcuse 1937: 62). Political and economic institutions and relationships have their own form of culture. Although it has a certain degree of autonomy, culture can only be thought of in connection with political and economic processes. The complex interplay of culture and politics is the area where hegemony-as a specific phenomenon of societies that are constituted by relationships of domination-is formed.

Figure 8 shows the processes of constitution and differentiation of social information. These processes form an integrated whole which encompasses the three subsystems of society (economics, politics and culture) and the manifestations of social information in these areas. Dispositions over resources can also be termed economic information, decisions on the societal circumstances of life may be seen as political information and definitions of the rules of living together as cultural information. Together we refer to them as social information. The productive forces (umwelt alias natural environment and the forces of the scientific-technological infrastructure) form the base for the emergence of economic information which itself forms the base for the emergence of political and cultural information. The whole social system encompasses three cycles of self-organisation which result in the emergence of social information on an economic, a political as well as a cultural level. On the one hand, economic information influences the emergence of political and cultural information and political information influences the emergence of cultural information in processes of bottom-up-emergence. On the other hand, cultural information influences the emergence of political and economical information and political information influences the emergence of economical information in processes of top-down-emergence. Nonetheless, economics and economical information form the base of every type of society.

Social co-operation can be seen as a social relationship in which the mutual references of the involved individuals (these are social interactions) enable all of them to benefit from the situation. By co-operating individuals can reach goals they would not be able to reach alone. New qualities of a social system can emerge by social co-operation. The elements/individuals of this system are conscious of these structures which can not be ascribed to single elements, but apply to the social whole which relates the individuals to each other. Such qualities are constituted in a collective process by all concerned individuals and are emergent qualities of social systems.

Social competition can be seen as a social relationship in which the social interactions as well as the relationships of domination enable some individuals or parts of society to take advantage of others. The first benefit at the expense of the latter, who have to deal with the disadvantages of the situation. New qualities of an observed social system can emerge through social competition. But these qualities are not constituted collectively by all concerned individuals, they are constituted by parts of society that dominate others, or can make use of advantages that derive from higher positions in existing social hierarchies.

Thus, social information can have a co-operative or a competitive character. This depends on the way it is constituted. If social information is established by mutual references of all individuals who are concerned by its application and if each involved individual has the same possibilities and means of influencing the resulting information structures in his/her own sense and interest, the resulting macroscopic structure is a form of co-operative social information. This type of information is collectively established by the co-operation of the concerned actors involved as an emergent quality of a social 
system in the process of self-organisation. We call this form of social information inclusive social information. Here self-organisation denotes that the individuals concerned by the emerging structures alone design the occurrence, form, course, and result of this process. They establish macroscopic structures via microscopic interrelations.

If social information is not constituted in processes of co-operation by all concerned individuals, but by a group of members of the relevant social system that dominates others, or can make use of advantages that derive from higher positions in existing social hierarchies, the resulting structures possess qualities that result from social competition-we speak here of exclusive social information. Exclusive social information is a new, emergent quality of a social system. It is constituted by social competition and reflects relationships of domination and the asymmetric distribution of property, power and influence. We can not say that exclusive social information is established in a process of social self-organisation because not all concerned individuals can participate in this process and influence it in the same way and access equally distributed resources and means.

Considering dissipative systems, self-organisation can be seen as the spontaneous emergence of patterns from the interactions of the system's elements if a certain threshold of relevant parameters is crossed. We argue in favour of emergent evolution which can make plausible new qualities of systems that emerge during the course of evolution and can not be reduced to lower levels of organisation/systems. Hence social systems are more complex than simple dissipative and simple autopoietic ones and self-organisation can not have exactly the same meaning as in less complex systems. In the course of the evolution of systems the complexity of the systems increases and new qualities of self-organisation emerge. These qualities have some similarities with the old meanings in less complex systems as well as new aspects. Hence on lower organisational levels we have a broader meaning of self-organisation. On upper levels this meaning is getting more and more specific because complexity increases. Therefore we argue in favour of an understanding of social self-organisation that not only considers the relationships of elements, but also looks at the qualities of these relationships. Thus class relationships as well as relationships of power and hegemony have to be considered.

A hierarchy is made up by a sequence which is ordered by the priority function. Individuals who are located at upper positions of a hierarchy have more capabilities of disposal over resources, of decision on societal matters and of definition of rules than individuals on lower levels. Hierarchies in society are characterised by the asymmetric distribution of capabilities. In our capitalist societies, scientifictechnological, ecological, economical, political and cultural information are formed in exclusive and asymmetrical ways. The scientific-technological development embodies interests of domination. The degradation of the natural environment is due to the short-sightedness of not taking into account the interests of all contemporary and future generations. Resources are owned and controlled by privileged and dominating classes. Value is being produced by dependent classes and groups which have no or minimal control over the productive forces, the means of production and material resources. In our western society which is politically formed by the model of representative democracy, the asymmetric distribution of power prevails. Last, not least there is an uneven access to the means of influence in cultural terms resulting in the hegemony of ruling classes.

Capitalist societies hence must be seen as class societies which are made possible by the exclusive control of social information. In capitalism, social information has an exclusive character and so we have to speak of exclusive economical, political and cultural information which is formed in a way that can not be considered self-organising in the full sense of the word. 


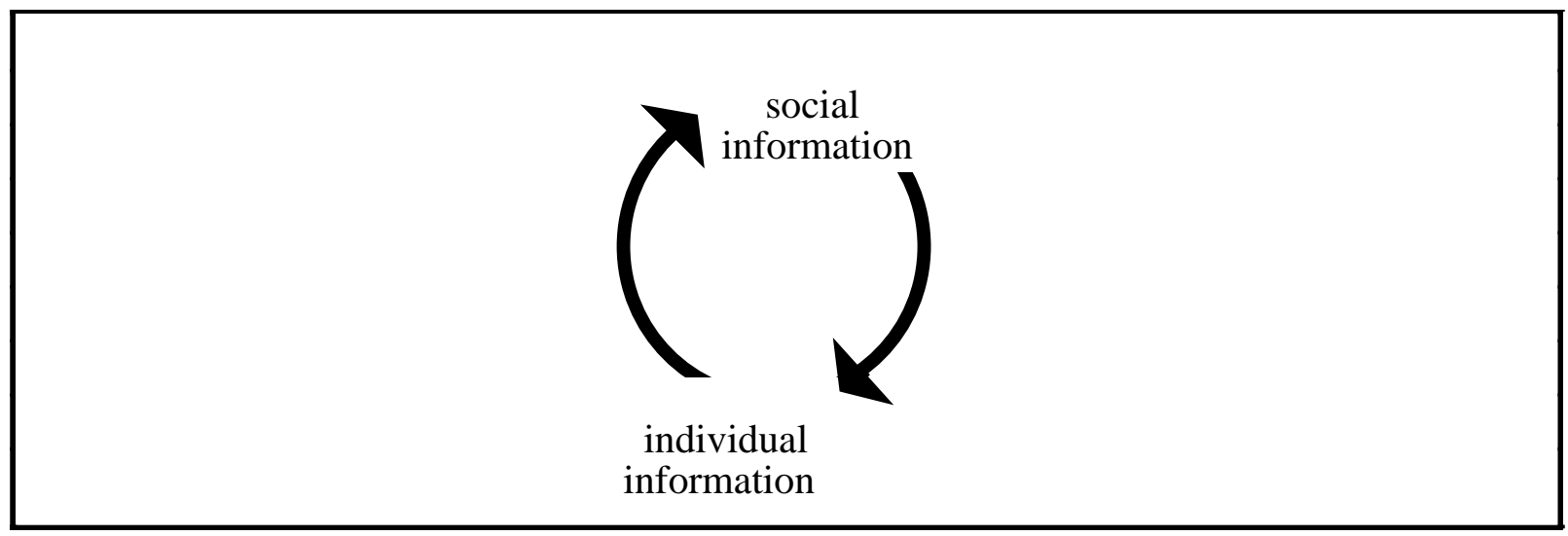

Fig. 9: Self-organisation in social systems: The dialectical relationship of individual and social information

Considering the relationship between individual and social information on the basis of self-organising processes, it can be said that by relating actions and hence individual consciousness of subjects socially, social information emerges. Social information can be seen as a type of social consciousness that emerges from the social relations of the individual consciousness of participating subjects in a social situation. A social system organises itself permanently in order to maintain and transcend itself and it permanently produces and changes social information. As shown in Figure 9 this is a dialectical process: Social information emerges from individual information. The subjects of society create and change social systems by relating their actions and hence their consciousness. New patterns emerge from this process. On the other hand we have a process of dominance: Individual consciousness can only exist under the umbrella of social processes and social information. Social information constrains and enables individual consciousness and action. In this dialectical relationship of individual and social information, we have the bottom-up-emergence of social information and the top-down-emergence of individual information. On the macroscopic level of the social system, new social information can emerge during the permanent selforganisation/re-creation of the system. On the microscopic level, social information makes an effect in a process of dominance and new individual information can emerge. So dominance can be seen as a type of top-down-emergence. The endless movement of individual and social information, i.e. the permanent emergence of new information in the system, is a two-fold dialectical process of self-organisation that is inherent to social system.

As already mentioned the signals as the starting point in the constitution and differentiation of individual information do not solely refer to objects of our environment, they also refer to social information. This is the way of establishing a relationship between individual and social information.

If cognition were solely determined by reflection, the exclusive social information we find in our society today would almost necessarily be reflected as individual information by everyone. But in fact almost nobody agrees with all the laws and political decisions. Everyone has a dynamically changing structure of individual information. But individual information often reflects the dominant conditions, norms, rules, habits and values of society. This reflection is established in processes of socialisation. Individuals are confronted with manipulation and disinformation by economy, politics, media, ideologies, and in personal relations. Because of the existing exclusions, the economically dominant classes control the channels which mediate information. Nonetheless the establishment of and the access to alternative channels which distribute underrepresented information is possible if individuals experience alternative forms of socialisation. But these individuals are confronted with the asymmetric distribution of power in society. Alternative channels and alternative socialisation can trigger the constitution of individual information that does not reflect the dominating exclusive social information. 
The epistemological aspect of information in social systems can be seen as the dialectical relationship between reflection and construction. Both are aspects of cognition. In the society we live in, the reflection of social conditions in our individual structure of cognition dominates the construction of the individual self. But such domination can never have a wholly determining character. Today, individual information can not be established in a self-conscious manner because diverse mechanisms of manipulation exist which estrange and restrict the self. This means that repressive forms of social information that are exclusive in character and form an integral part of modern society dominate the self-conscious construction of individual information. The relationship of individual and social information surely is a dialectical one. But it can be said that in our modern society exclusive social information dominates information that is inclusive and mechanisms of social manipulation dominate the self-conscious construction of individual information. Hence in analysing the relationship of being and consciousness, structuralist approaches like the ones of Adorno or Marcuse seem to be more realistic than constructivist ones. Nonetheless it is important to stress that today social structures though dominating self-consciousness, do not determine them, and that consciousness can not be constructed autonomously or outside social structures. If these assumptions are not made, one either does not leave room for the possibility of transforming society basically (as is the case with orthodox structuralism) or one does not consider that society and individuality should be changed (as constructivism does).

If we again take a look at figure 9 which shows the dialectical process of re-creation in social systems, it can be seen that in modern society the structuralist aspect of this two-fold process, i.e. the constraining of individual information by social information, dominates the options of individuals to participate in the bottom-up-process of establishing social information. In our society, the process of creation and differentiation of social information is dominated by ruling classes and elites. This is a process that excludes the majority of the individuals that are affected by social information. This majority participates only in a rudimentary way in the bottom-up-process, but nonetheless its actions and thinking are greatly restricted by the emerging exclusive social information.

Relating being and consciousness dialectically involves an emergent approach that on the one hand considers that society emerges from the social relationships of individuals who relate their individual social information-structures in order to establish or differentiate social information. This is a bottom-up process in which social information emerges from individual information. On the other hand social information transforms individual information in a top-down-process. It both constrains and enables individual performance and thinking. So new individual information can only emerge in relationship to social information. The important question is if this relationship of individual and social information is socially designed in an inclusive or an exclusive manner. And this is clearly dependent upon social, political and economical relationships. In modern capitalist society, social information has an exclusive character and negative constraints on individual consciousness, information and action. It is important to stress that such a dialectical concept of relating society to individuality involves two types of emergent processes: The bottom-up-emergence of social information and the top-down-emergence of individual information.

Thus far we have not been able to dispose of diverse manipulations in society, which trigger the domination of social competition and exclusive social information, in order to become self-determining, autonomous and altruistic individuals that alone can choose and differentiate their individual and social information. As Marcuse pointed out, a society that allows individuality to flourish freely can only be established by self-organising individuals (in the political sense): "The individuals who shall live in the Great Society must be the ones who build it up-they must be free for it, before they can be free in it. No other power can impose or force their society upon them" (Marcuse 1966: 187).

Individual and collective interests could be compatible without interfering with each other. Egoism is not a "natural" pattern of behaviour given at birth or encoded in the genes; rather it is brought forth by processes of socialisation in a system dominated by competition and exclusive social information. 
Individual information and social information could both possess the character of freedom because social information would emerge as a quality of social co-operation in a process of self-organisation from individual information. The emergence of individual information would be made possible by inclusive social information. Nonetheless, individual information would still change dynamically with new social experiences.

The world-system we live in is in a major crisis. This crisis surely has technological, ecological, economic, political and cultural causes. Global problems have become a major threat to humanity. We are at a social and a historic crossroads today: The future development of society is not pre-determined, but if the path of evolution does not change fundamentally, the end of mankind and the breakdown of our world system could occur in the decades to come. But mankind has not been abandoned to some kind of predetermined fate, because there are alternative evolutionary developments.

Immanuel Wallerstein also points out that this crisis can be seen as a crossroads of the historical development of society: "...this structural crisis leads us into a dark period of struggle over what kind of system will succeed the existing one. We can think of this as a bifurcation, and therefore the beginning of a chaotic period, within which no one can predict the outcome, which is inherently indeterminate. There will be a new structure, a new order, but it may be either better or worse than the existing one. It depends on what we all do in the period of acute struggle and how clearly we understand the forces at work" (Wallerstein 1999b; see also Wallerstein 1997a, 1997b, 1998, 1999a, 2000; Hopkins/Wallerstein 1996).

One of the factors responsible for the major crisis of the world system is the antagonism of co-operation and competition, which is characteristic of modern/capitalist society. Competitive processes and the logic of commodities dominate inclusive and co-operative social relationships. Social information today is predominantly an exclusive one. A way out of the crisis that points to a qualitatively new evolutionary path and is socially, ecologically and technologically sustainable could be established by the real selforganisation of the individuals that are confronted by the negative effects of global problems. The breakdown of the world system would mean the destruction of society's permanent re-creation-process. In order to maintain the re-creation of society, people who are excluded from the bottom-up-process, which establishes social information, and who are exploited in order to maintain the exclusive character of society would have to organise themselves, in the political sense of the term. A change of dominance is necessary in order to solve our global problems and to save humanity from self-destruction: The dominance of co-operation by competition, of inclusive social information by exclusive social information has to be reversed. If this can be done, a just, good and beautiful society may be established that managed to dispose of its global problems. The principles of such a society would be true social selforganisation and they would include social information.

\section{References:}

Adorno, Theodor W. (1956) Soziologische Exkurse [Sociological Excursions]. Frankfurt/Main. Europäische Verlagsanstalt.

Adorno, Theodor W. (1970) Aufsätze zur Gesellschaftstheorie und Methodologie [Essays on Sociology and Methodology]. Frankfurt/Main. Suhrkamp

Alexander, Jeffrey C. (1995) Fin de Siecle Social Theory - Relativism, Reduction, and the Problem of Reason. London etc. Verso Artigiani, Robert (1991) Social Evolution. A Nonequilibrium Systems Model. In: Laszlo, Ervin (Ed.) (1991) The New Evolutionary Paradigm. New York, NY. Gordon and Breach

Engels, Frederick (1847) Principles of Communism (in German). MEW, Vol. 4. pp 361-380

Engels, Frederick (1886) Ludwig Feuerbach and the End of Classical German Philosophy (in German). MEW, Vol. 21. pp. 259-307.

Fenzl, Norbert/Hofkirchner, Wolfgang/Stockinger, Gottfried (1998) Information und Selbstorganisation. Annäherungen an eine vereinheitlichte Theorie der Information [Information and Self-Organisation]. Wien/Innsbruck. Studien Verlag

Fleissner, Peter and Hofkirchner, Wolfgang (1997) Actio non est reactio. An Extension of the Concept of Causality towards Phenomena of Information. In: World Futures 49/3-4 \& 50/1-4

Foucault, Michel (1976) Überwachen und Strafen. Die Geburt des Gefängnisses [Discipline and Punish: The Birth of the Prison] Frankfurt/Main. Suhrkamp. Neuauflage 1994 
Fuchs, Christian (2000) Selbstorganisation in der Informationsgesellschaft [Self-Organisation in the Information-Society]. Wien. Online Version: http://stud4.tuwien.ac.at/ e9426503

Fuchs, Christian (2001) Soziale Selbstorganisation im informationsgesellschaftlichen Kapitalismus. Gesellschaftliche Verhältnisse heute und Möglichkeiten zukünftiger Transformationen [Social Self-Organisation in Information-Societal Capitalism. Social Relations today and Possibilities of Future Transformations]. Wien/Norderstedt. Libri Books on Demand.

Fuchs, Christian (2003a) Some Implications of Pierre Bourdieu's Works for a Theory of Social Self-Organization. In: European Journal of Social Theory, Vol. 6, No. 4, pp. 387-408.

Fuchs, Christian (2003b) Structuration Theory and Self-Organization. In: Systemic Practice and Action Research, Vol. 16 (2003), No. 4. pp. 133-167.

Giddens, Anthony (1984) The Constitution of Society. Cambridge. University of California Press

Giddens, Anthony (1997) Die Konstitution der Gesellschaft. Frankfurt/Main. Campus. 3. Auflage

Gramsci, Antonio (1930/31a) Base and Superstructure. In: Gramsci (1980). pp 219f (in German)

Gramsci, Antonio (1930/31b) Philosophical Notices about Materialism and Idealism. In: Gramsci (1980). pp 221f

Gramsci, Antonio (1934) Art and Culture. In: Gramsci (1980). p. 244 (in German)

Gramsci, Antonio (1980) Zu Politik, Geschichte und Kultur. Leipzig. Reclam

Heylighen, Francis (1990) Self-steering and cognition in complex systems. Toward a new cybernetics. New York u.a. Gordon and Breach

Hofkirchner, Wolfgang (1998) Emergence and the Logic of Explanation. An Argument for the Unity of Science. In: Acta Polytechnica Scandinavica, Mathematics, Computing and Management in Engineering Series 91, 23-30

Hofkirchner, Wolfgang (1999a) Cognitive Sciences in the Perspective of a Unified Theory of Information. In: Allen, J. K., Hall, M. L. W., Wilby, J. (Eds.), Proceedings of the 43rd Annual Conference of ISSS (The International Society for the Systems Sciences), ISBN 09664183-2-8 (CD-ROM)

Hofkirchner, Wolfgang (Ed.) (1999b) The Quest for a Unified Theory of Information. Proceedings of the Second Conference on the Foundations of Information Science. Amsterdam etc. Gordon and Breach

Hofkirchner, Wolfgang (2002) Projekt Eine Welt. Oder Kognition Kommunikation Kooperation. Versuch über die Selbstorganisation der Informationsgesellschaft [Project One World: Or Cognition Communication Cooperation. Attempt at the Self-Organisation of the Information-Society]. Münster. LitVerlag

Hopkins, Terence/Wallerstein, Immanuel (1996) The Age of Transition. Trajectory of the World-System, 1945 - 2025. London. Zed Books.

Horkheimer, Max/Adorno, Theodor W. (1972) Dialectic of Enlightenment. New York. Herder and Herder. New York.

Marcuse, Herbert (1937) About the Affirmative Character of Culture. In: Kultur und Gesellschaft 1. Frankfurt/Main. Suhrkamp. pp 102-127

Marcuse, Herbert (1966) Das Individuum in der Great Society [The Individual in the Great Society]. In: Marcuse Schriften 8. pp 167193

Marcuse, Herbert (1967) Der eindimensionale Mensch: Studien zur Ideologie der fortgeschrittenen Industriegesellschaft [OneDimensional Man]. München. dtv. Neuauflage 1994

Marcuse, Herbert (1969) Versuch über die Befreiung [Essay on Liberation]. In: Marcuse Schriften 8. pp 237-317

Marx, Karl/Engels, Frederick (1845/46) The German Ideology (in German). MEW, Vol. 3. pp 5-530

Marx (1852) The Eighteenth Brumaire of Louis Bonaparte (in German). MEW, Vol. 8. pp 111-207

Marx, Karl (1867) Theses on Feuerbach (in German). MEW, Vol. 3. pp 533ff

Marx, Karl (1867) Capital. Volume 1 (in German). MEW. Vol. 23

Maturana, Humberto R., Varela, Francisco J. (1984) Der Baum der Erkenntnis. Die biologischen Wurzeln des menschlichen Erkennens [Tree of Knowledge]. Bern/München/Wien. Scherz, , $3^{\text {rd }}$ edition 1987

Maturana, Humberto R. (1988) Reality: The Search for Objectivity or the Quest for a Compelling Argument. In: The Irish Journal of Psychology. 1988, 9, 1. pp 25-82

MEW Marx, Karl/Engels, Frederick Collected Works (in German). Berlin. Dietz

Mouzelis, Nicos (1995) Sociological Theory. What went wrong? Diagnosis and Remedies. London etc. Routledge

Popper, K. R. (1972): Objective Knowledge. An Evolutionary Approach. Oxford

Popper, K. R., J. C. Eccles (1977): The Self and Its Brain. Berlin etc.

Prigogine, llya (1980) From Being to Becoming. New York. Freeman

Reckwitz, Andreas (1997) Struktur. Zur sozialwissenschaftlichen Analyse von Regeln und Regelmäigkeiten. Opladen. Westdeutscher Verlag

Salthe, Stanley N. (1996) Development and Evolution. Cambridge, MA. MIT Press

Thompson, Edward P. (1961) Review of Raymond Williams' The Long Revolution. In: Munns, Jessica/Rajan, Gita (Eds.) (1995) A Cultural Studies Reader. London. S. 155-162

Wallerstein, Immanuel (1997a) The End of Certainties in the Social Sciences. Talk at the Seminar "Conceptos en Ciencias y Humanidades. Mexico City, Oct. 16, 1998. http://fbc.binghamton.edu/iwendcrt.htm

Wallerstein, Immanuel (1997b) Uncertainty and Creativity. Talk at Forum 2000: Concerns and Hopes on the Threshold of the New Millennium. Prague, Sept. 3-6, 1997. http://fbc.binghamton.edu/iwuncer.htm 
Wallerstein, Immanuel (1998) Utopistics: or, Historical Choices for the Twenty-First Century. New York. New Press Wallerstein, Immanel (1999a) Globalization or the Age of Transition? A Long-Term View of the World-System. http://fbc.binghamton.edu/iwtrajws.htm

Wallerstein, Immanuel (1999b) Uncertainty and Historical Progress. http://fbc.binghamton.edu/iwposb.htm Wallerstein, Immanuel (2000) Ab abschüssiger Strecke mit defekten Bremsen. In: Le Monde Diplomatique (German Edition). $11 / 08 / 2000$

http://monde-diplomatique.de/mtpl/2000/08/11/a0037.stext?Name=askp6VVBa\&idx=1

Williams, Raymond (1961) The Long Revolution. London 